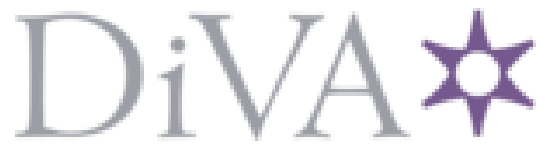

http://www.diva-portal.org

Postprint

This is the accepted version of a paper presented at 22nd International Conference on Electrical Machines (ICEM), SEP 04-07, 2016, Lausanne, SWITZERLAND.

Citation for the original published paper:

Eklund, P., Eriksson, S. (2016)

Air Gap Magnetic Flux Density Variations due to Manufacturing Tolerances in a

Permanent Magnet Synchronous Generator

In: 2016 XXII INTERNATIONAL CONFERENCE ON ELECTRICAL MACHINES

(ICEM) (pp. 93-99). IEEE

https://doi.org/10.1109/ICELMACH.2016.7732511

N.B. When citing this work, cite the original published paper.

Permanent link to this version:

http://urn.kb.se/resolve?urn=urn:nbn:se:uu:diva-292962 


\title{
Air Gap Magnetic Flux Density Variations due to Manufacturing Tolerances in a Permanent Magnet Synchronous Generator
}

\author{
Petter Eklund and Sandra Eriksson
}

\begin{abstract}
The impact of manufacturing tolerances on the performance of a permanent magnet synchronous generator is investigated. A generator with a flux concentrating spoketype rotor, with ferrite permanent magnets, is used in the investigation. Measurements of the air gap magnetic flux density, the air gap length, as well as the magnetization and size of the permanent magnets have been performed. Correlations are calculated and causalities are discussed. It is found that the permanent magnets used are below tolerance in remanent magnetic flux density, that the air gap length is smaller than specified, and that the resulting air gap magnetic flux density is lower than specified. From the results it can be concluded that the design should be made with tolerances in mind and that quality control of parts, especially of PM magnetization, is important for machine performance.
\end{abstract}

Index Terms-Ferrites, generators, permanent magnet machines, permanent magnets.

\section{INTRODUCTION}

At Uppsala University, research of permanent magnet (PM) synchronous generators (SG) for renewable energy applications is ongoing. In response to the 2011 cost increase of neodymium-iron-boron (NdFeB) PMs there has been work on permanent magnet synchronous generators (PMSGs) using other, less expensive, rare earth metal-free kinds of PMs [1]. The design of one such PMSG is described in [2]; where a ferrite PM rotor is designed to replace a NdFeB PM rotor, while preserving the electrical properties of the machine. A generator has been retrofitted with the ferrite PM rotor, and is currently being experimentally evaluated. The choice of ferrite was due to it being a commonly available PM material with low and stable cost. There are some earlier studies on ferrite PMSGs published, see for instance [3] and [4].

In this paper, it is investigated how the air gap magnetic flux density deviates from the design calculations, due to manufacturing tolerances of different parts of a PMSG. The PMSG has a flux concentrating spoke-type rotor using ferrite PMs. The tolerances investigated are both geometrical and magnetic.

This study was carried out with funding from the Swedish Research Council, Grant Number 2012-4706. The experimental setup was financed by Ångpanneföreningen's Foundation for R\&D, Grant number 12-295. This work was conducted within the StandUP for Energy strategic research framework.

P. Eklund and S. Eriksson are with the Division of Electricity, Department of Engineering Sciences, Uppsala Universitet, SE-752 37 Uppsala, Sweden (e-mail: petter.eklund@angstrom.uu.se, sandra.eriksson@angstrom.uu.se).

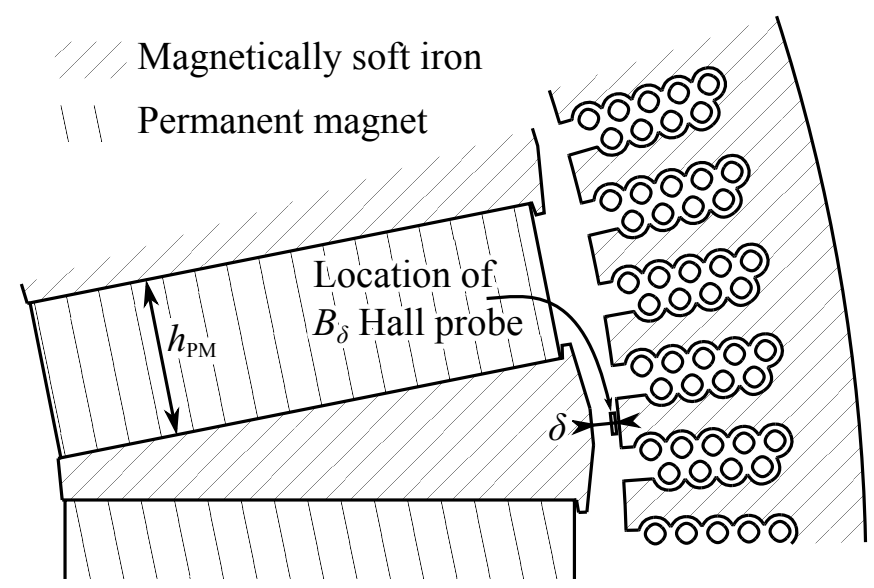

Fig. 1. A cross section of the magnetic circuit indicating some of the measured quantities: air gap length $(\delta)$, PM thickness $\left(h_{\mathrm{PM}}\right)$ and the location of the air gap magnetic flux density measurement $\left(B_{\delta}\right)$. The magnetization of the PMs is parallel to the short side of the PM, and of alternating polarity, such that each pole piece is placed between two PM poles of the same kind.

Previous work on the impact of tolerances in PM synchronous machines has mainly been focused on the effects on the cogging torque in motors, with the number of poles in the range of 6 to 10 [5]-[7], as well as one study on a 20 pole axial flux PM motor [8]. Earlier work on tolerances in manypole PMSGs has investigated the impact of the variability of PM material properties on losses through simulations [9]. There is also earlier work experimentally investigating the impact of the air gap length varying between poles on the output voltage [10].

\section{The InVESTigated PM Generator}

The generator in this study has a flux concentrating spoketype rotor, the concept is shown in Fig. 1. Some nominal design parameters of the generator are given in Table I and more details about the design are given in [2]. The PMs are in the shape of rectangular blocks and placed between two pole pieces, which are made from magnetically soft steel. The magnetization of a PM is directed along its shortest side, which is approximately parallel to the rotor periphery, and of alternating polarity such that each pole piece is situated between two PM poles of the same type. The pole piece concentrates and guides the magnetic flux into the air gap. This allows the air gap flux density to exceed the remanent flux density of the PM; as the combined width of the PMs 
TABLE I

Nominal Parameters for the GEnERATOR USEd In the StUdy.

\begin{tabular}{lc} 
Parameter & Value \\
\hline Stator inner diameter & $760 \mathrm{~mm}$ \\
Active machine length & $224 \mathrm{~mm}$ \\
air gap length $(\delta)$ & $7 \mathrm{~mm}$ \\
Number of poles & 32 \\
Rotational speed & $127 \mathrm{rpm}$ \\
No load phase voltage (RMS) & $146 \mathrm{~V}$ \\
Power & $12 \mathrm{~kW}$
\end{tabular}

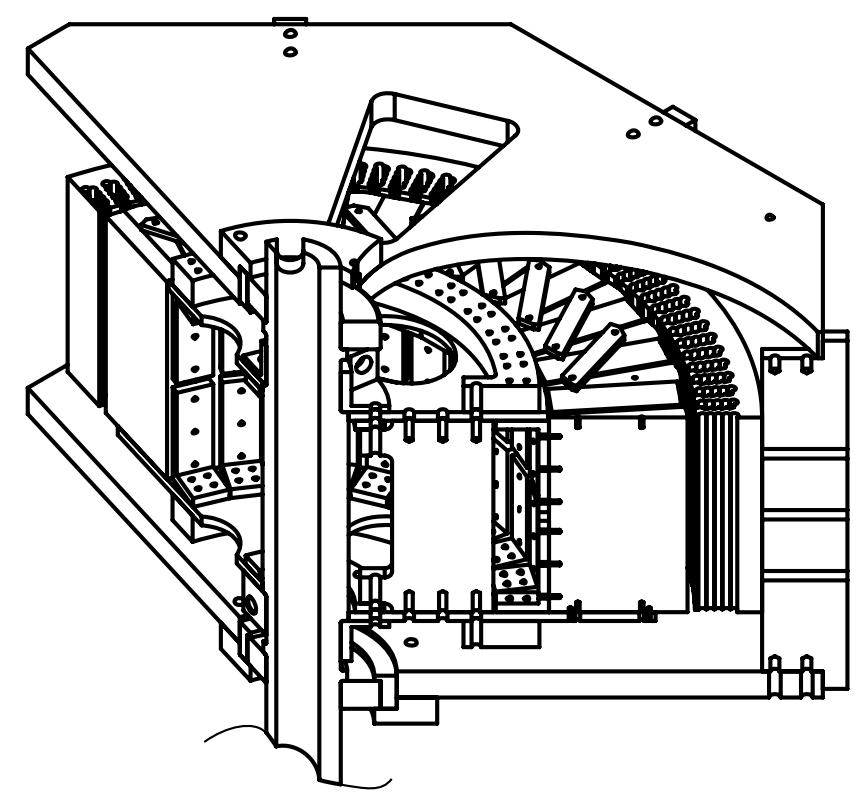

Fig. 2. Isometric cutaway drawing showing the mechanical structure of the generator. The right cut is through a pole center and the left cut is in the boundary between two poles. Some of the generator composite end board has been cut away to better show the structure of the rotor. While the stator is made up from laminated electrical plates it is depicted as solid to avoid clutter.

abutting a pole piece is larger than the pole pitch. This flux concentration is important for low remanence PM materials, such as hard ferrite.

The spoke-type rotor is mechanically more complex than a surface mounted PM rotor, which is a common design when using NdFeB PMs. The PMs and flux concentrating pole pieces need to form a closed ring, with little or no gap between the pieces. A narrow tolerance on the outer diameter is also needed. The pole pieces need to be held in place by a nonmagnetic support structure to avoid leakage flux, while the pole pieces themselves need to be magnetic.

The mechanical structure of the generator is shown in Fig. 2. The structure is self-supporting with two glass fiber composite end boards holding both the stator and rotor in place. The stator is attached to the end boards using bars made from nonmagnetic stainless steel. The bearing housings are fitted directly into holes in the end boards, relying on the precision of the end boards, with a tolerance of $\pm 0.1 \mathrm{~mm}$ on the position accuracy of the hole, to center the rotor in the stator. The unbalanced magnetic pull (UMP) caused by a $3 \mathrm{~mm}$ off-center rotor is calculated to about $10 \mathrm{kN}$. This is well below the force required to pull the rotor $3 \mathrm{~mm}$ offcenter.

The rotor pole pieces are mounted on a rotor bottom plate, which is made from aluminum. Both the rotor bottom plate and pole pieces have holes where slotted spring pins are inserted to ensure proper positioning of the pole pieces. The parts are machined to narrow tolerances, $\pm 0.1 \mathrm{~mm}$ for the location of the holes, to ensure correct placement of the pole pieces. To center the rotor bottom plate on the shaft a narrow clearance fit is used. The pole pieces are also attached to the rotor end plates using L-shaped pole piece holders. The rotor end plates are fixed on the shaft using flanges that are bolted together.

The PMs are inserted into slots between the pole pieces. They are made from multiple pieces of magnetically hard ferrite of grade Y40, joined together to a block with an adhesive. The PMs are radially and tangentially held in place by the pole pieces and the pole piece holders. In the axial direction each PM is held in place by the rotor bottom plate, which partially blocks one end of the slot between two pole pieces, and a small bar made from aluminum that is bolted to the other end of the pole pieces surrounding the PM.

During assembly it was found that nearly half of the PMs were above tolerance in thickness. Considerable force was needed to insert the PMs into their slots, even though the design was made to allow some clearance at the upper tolerance limit of thickness. The use of force caused a few magnets to crack slightly. The cracking caused some flakes of PM material to break away and contaminate the air gap. In the worst case about $0.03 \mathrm{~kg}$ of PM material flakes were removed from the air gap after inserting a PM with a mass of $5.1 \mathrm{~kg}$. While the larger flakes could be removed with relative ease, many of the smaller flakes proved challenging to remove.

\section{AIM AND METHOD}

The aim of this study is to investigate how deviations from nominal values of air gap length, and PM magnetization and size, affect the air gap magnetic flux density in a PMSG with a spoke-type rotor using ferrite PM, and how interpole variations in air gap magnetic flux density affect output voltage and UMP.

The investigation is carried out mainly by experiment, with some support from simulations. Experiments are performed on the machine described in Section II, built according to the design described in [2], and simulations are performed using finite elements analysis software.

The air gap length, $\delta$, for a fixed point on the stator is measured using cylindrical gauge taps. The measurement is performed between a stator tooth and the flat surface in the middle of the pole face, as indicated in Fig. 1. Increasing sizes of taps are tried until the smallest diameter that will not fit is found. The set of taps is made so that the difference in diameter between two taps is less than $0.1 \mathrm{~mm}$, to get adequate resolution. The diameters of the cylindrical part 
of the taps are checked using a micrometer. The difference between minimum and maximum diameter, depending on the angle, is less than $0.02 \mathrm{~mm}$ for all taps. The center of the span is used as the nominal diameter of the tap.

The procedure for inserting the tap starts by wiping the pole face clean; to avoid that any dirt disturbs the measurement. Then the tap is inserted by twisting, turning, tapping, and shaking the tap by hand, but not using any additional tools. To be considered to fit, the cylinder should be possible to insert at least $15 \mathrm{~mm}$. The cylindrical part of nominal diameter of the taps is about $5 \mathrm{~mm}$ in length, then there is a handle of smaller diameter with a length of about $60 \mathrm{~mm}$.

During the measurements, it is found that sometimes a tap too large to be inserted from the top can be swiped sideways past the same pole some way down into the air gap. In order to measure this, two measurement series of the air gap length are recorded: $\mathrm{T}$ and $\mathrm{S}$. The $\mathrm{T}$ measurements are the diameter of the largest tap that can be inserted from the top for a pole. The $\mathrm{S}$ measurements are the diameter of the largest tap that can be swept past the pole further into the air gap. The stator is assumed to be round and of nominal inner diameter, since measurement of the inner diameter is not possible in more than a narrow sector where there are holes in the end board for insertion of the PMs.

The air gap magnetic flux density, $B_{\delta}$, is measured by fixing a calibrated Hall probe in a position in the air gap. The Hall probe used is a FW Bell 5180 Gauss/Tesla meter. The position of the measurement is about $50 \mathrm{~mm}$ down into the air gap, in front of the same stator tooth that is used for the air gap length measurements. The approximate location in the plane of rotation is shown in Fig. 1. The Hall probe is oriented to measure the radial component of the air gap magnetic flux density. The distance from the probe to the stator inner surface is approximately $1 \mathrm{~mm}$. To get consistent angular position of the rotor pole during measurement, two pieces of paper are fixed relative to the stator, with some distance in between, to form a simple sight. When in the correct position the edge of the rotor pole pieces aligns with the edges of the pieces of paper. The initial plan was to both measure the magnetic flux density at the pole center, and to find the maximum magnitude of each pole, but after measuring a few poles it became apparent that these coincided without exception.

The magnetization of each PM is indirectly measured before mounting them in the machine. This is done by placing the PM far from any other ferromagnetic object, and measuring the normal component of the magnetic flux density on the surface of the PM, at the center of the pole face,

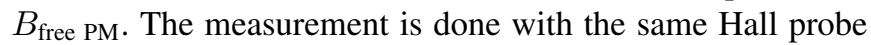
that is used for the $B_{\delta}$ measurement. From this measurement the remanent flux density, $B_{r}$, of the PM can be calculated. This is done by simulating the PM inside a large sphere of free space, using the finite element method to solve for the magnetic scalar potential. The constitutive equation used for the $\mathrm{PM}$ is

$$
\boldsymbol{B}=\boldsymbol{B}_{r}+\mu_{0} \mu_{\mathrm{rec}} \boldsymbol{H}
$$

where $\boldsymbol{B}$ is the magnetic flux density; $\boldsymbol{B}_{r}$ is the remanence, directed along the short edge of the PM; $\mu_{0}$ the permeability of free space; $\mu_{\text {rec }}$ the recoil permeability of the PM; and $\boldsymbol{H}$ the magnetizing field. The recoil permeability is calculated from the manufacturer's specification by assuming that the maximum energy product, $|B H|_{\max }$, is in the linear part of the $B H$-curve. This allows the recoil permeability to be calculated as

$$
\mu_{\mathrm{rec}}=\frac{B_{r}^{2}}{4 \mu_{0}|B H|_{\max }}
$$

where $B_{r}$ and $|B H|_{\max }$ are taken from the PM material data sheet. From the simulations a table of magnetic flux densities in the measured point for a given $B_{r}$ is made. By interpolation in this table, $B_{r}$ of each PM can be calculated from $B_{\text {free PM. }}$

A no load test where the generator is spun up by hand, and allowed to free-wheel while the terminal voltages are measured is performed. The rotational speed during the test is determined. To test the accuracy of the simulation method used in [2], a no load simulation with mean values of measured $\delta$ and $B_{r}$ at the determined speed is made. The simulated magnetic flux density in the measurement point and the output voltage are compared to the measurements.

The Hall probe magnetometer has a specified accuracy of $\pm(0.6 \%+0.3 \mathrm{mT})$ for the range used to measure $B_{\text {free PM}}$; the percentage is of the measured value. To this value a linearity of the probe itself of $\pm 0.5 \%$ of the measured value has to be added. For the range used to measure $B_{\delta}$ the specified accuracy is $\pm(0.6 \%+3 \mathrm{mT})$.

The error of the micrometer should be below its resolution of $0.01 \mathrm{~mm}$. The taps are measured to be within $\pm 0.01 \mathrm{~mm}$ of their nominal diameter, and the step in diameter is $0.09 \mathrm{~mm}$ at most. This means that the air gap length should have an accuracy of $-0.02 \mathrm{~mm}$ to $+0.11 \mathrm{~mm}$ at worst.

The thickness of a PM, $h_{\mathrm{PM}}$, is measured using a vernier caliper with a resolution of $0.1 \mathrm{~mm}$. The grading of the vernier scale of the caliper used is narrow and hard to read, giving an accuracy of $\pm 0.1 \mathrm{~mm}$ at best. Further some of the PMs have sides that are not perfectly parallel making the measured value a minimum of the thickness.

To investigate correlation between the measured variables correlation coefficients are used. Given two sampled variables $x_{i}$ and $y_{i}$ sampled for $i=1,2, \ldots N$, the correlation coefficient is computed by

$$
r_{x, y}=\frac{\sum_{i=1}^{N}\left(x_{i}-\bar{x}\right)\left(y_{i}-\bar{y}\right)}{\sqrt{\sum_{i=1}^{N}\left(x_{i}-\bar{x}\right)^{2} \sum_{i=1}^{N}\left(y_{i}-\bar{y}\right)^{2}}}
$$

where bar above a variable indicates the arithmetic mean. The correlation coefficient will have a value between -1 and 1 with either extreme indicating a perfectly linear relationship between the variables with the same sign as the coefficient. 
Lesser magnitude of the coefficient can either be due to the relation not being linear, or due to random variations in the data. While, for instance, the relationship between air gap magnetic flux density and air gap length can be expected to be inverse, the variation in the latter should be small enough for a linearizion to be a good approximation.

The correlation coefficients are calculated for all combinations of $B_{\delta}, \delta, h_{\mathrm{PM}}$ and $B_{\text {free PM. In addition, for air }}$ gap length and PM thickness the correlation coefficients are computed with the data shifted up to \pm 16 poles. This is done to investigate if the thickness of the PMs can affect the air gap length a few poles away.

Inter-pole variation in the radial component of the air gap magnetic flux density, $B_{\delta, r}$, can cause an UMP. To estimate the UMP at standstill from the measurements done $B_{\delta, r}$ is approximated by

$$
B_{\delta, r}\left(\theta_{e l}\right)=B_{\delta i} \sin \left(\theta_{e l}\right)
$$

for pole $i$, where $B_{\delta i}$ is the peak value of the air gap magnetic flux density measured for pole $i$ and $\theta_{e l}$ the electrical angle. This is then used to calculate the Maxwell stress tensor through a cylindrical surface in the air gap. The force on pole $i$ is given by integration over the part of the cylinder in front of it as

$$
F_{i}=l \int_{0}^{\pi} \frac{\left(B_{\delta i} \sin \left(\theta_{e l}\right)\right)^{2}}{\mu_{0}} \frac{D / 2}{p / 2} \mathrm{~d} \theta_{e l}=\frac{l D}{\mu_{0} p} B_{\delta}{ }^{2} \frac{\pi}{2}
$$

where $D$ is the diameter of the cylindrical surface, $p$ the number of poles and $l$ the machine length. The force of each pole is assumed to be directed radially outward and the total UMP force is calculated as

$$
\boldsymbol{F}_{U M P}=\sum_{i=1}^{p} F_{i} \cdot(\hat{x} \cos (2 \pi i / p)+\hat{y} \sin (2 \pi i / p))
$$

where $\hat{x}$ and $\hat{y}$ are basis vectors of a Cartesian coordinate system with its $z$-axis along the axis of rotation and the $x$ axis passing through the center of the $p$ th pole.

\section{Results}

The raw measurement data are presented first and then the results of the statistical analysis.

The per pole peak value of the radial component of the air gap magnetic flux density, $B_{\delta}$, is shown in Fig. 3. It varies between $572 \mathrm{mT}$ and $639 \mathrm{mT}$, with a mean of $610 \mathrm{mT}$ and a standard deviation of $16.7 \mathrm{mT}$.

The magnetic flux density in the middle of the pole surface of each PM when placed far from other ferromagnetic objects, $B_{\text {free PM }}$, is shown in Fig. 4 . The field of the PMs placed at $276^{\circ}$ is significantly lower than for the others, $36 \mathrm{mT}$ compared to $61 \mathrm{mT}$ for the second lowest. It is suspected that the measurement point coincided with the joint between two of the pieces of ferrite making up the PM block, causing this anomalous measurement. Further, no significant change in the air gap field is observed for the poles adjacent to the anomalous PM. The poles adjacent to it

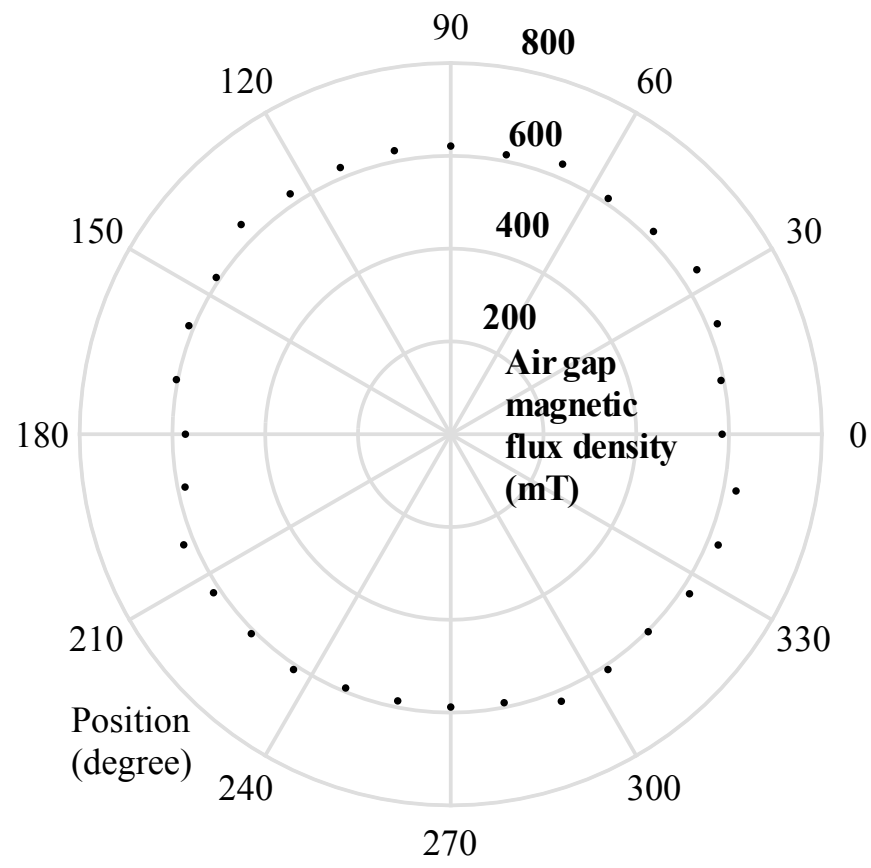

Fig. 3. Per pole maximum magnetic flux density in the air gap, $B_{\delta}$. Measurement position in axial direction: about $50 \mathrm{~mm}$ from the top into the air gap.

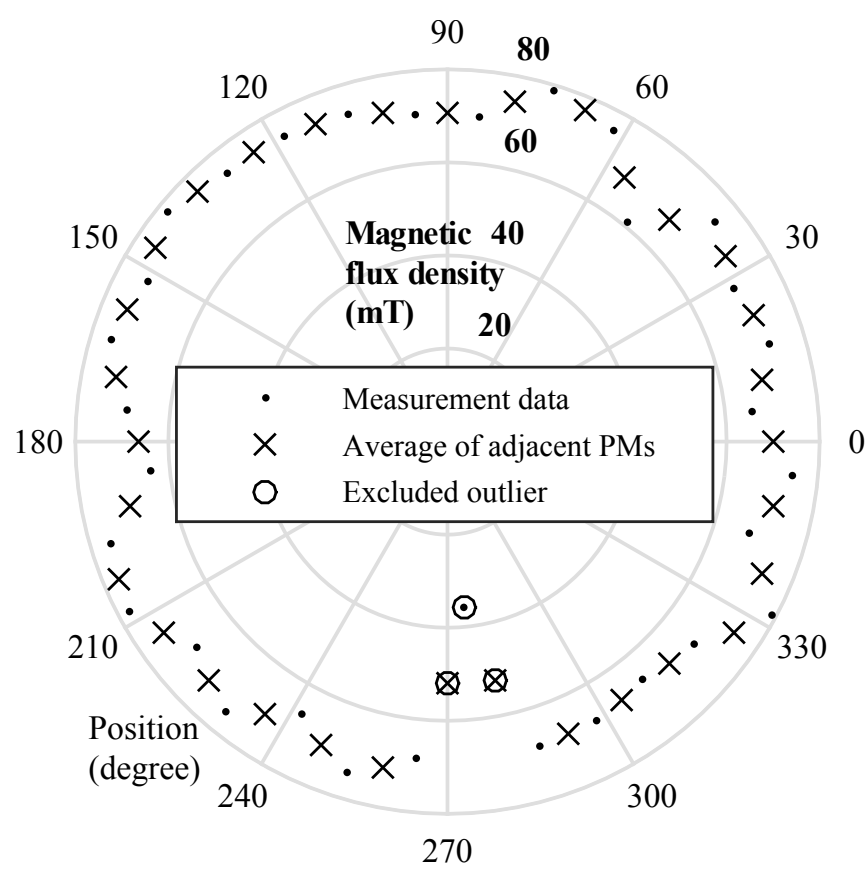

Fig. 4. Magnetic flux density in the middle of the pole surface of a free lying PM placed far from other ferromagnetic objects, $B_{\text {free PM. Both the }}$ measurement data and per pole means are plotted. The outliers excluded from the statistical analysis are indicated.

have, therefore, been excluded from the analysis; as the data point is considered to be an outlier. With the outlier excluded

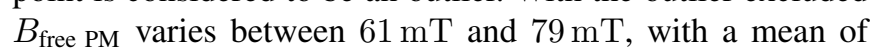
$71.6 \mathrm{mT}$ and a standard deviation of $4.6 \mathrm{mT}$.

The two different measurement series of air gap length, 


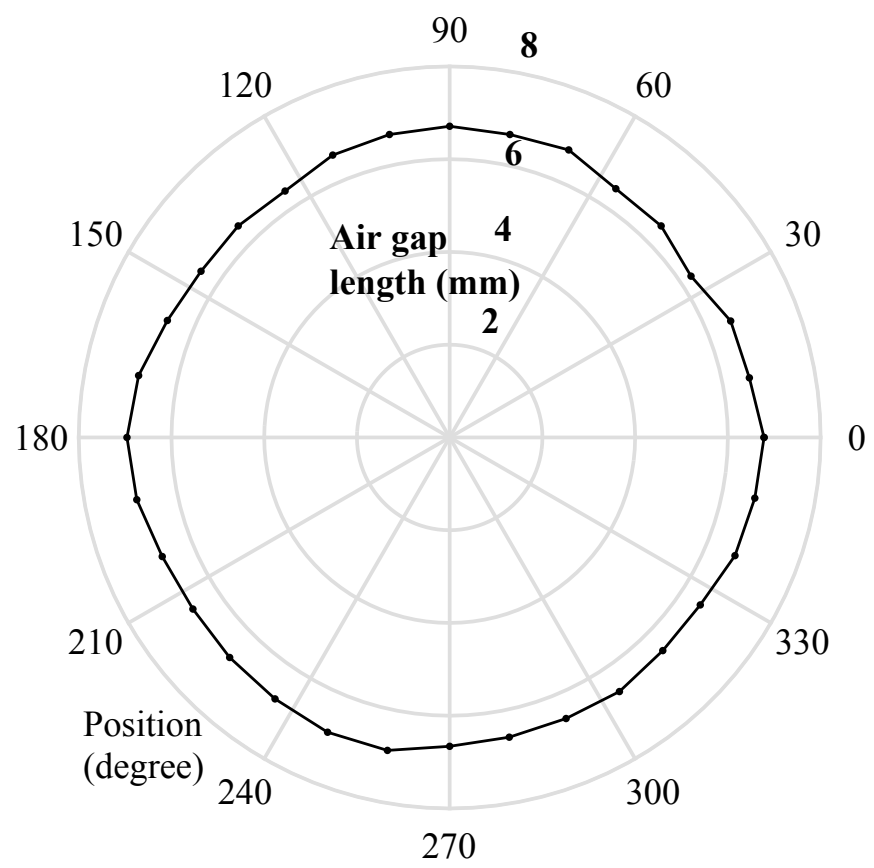

Fig. 5. Mechanical air gap length, $\delta$, measured between a fixed point on the stator and the center of each pole. Only measurement series $\mathrm{S}$ is given.

TABLE II

TABle of Correlation Coefficients. Values Calculated

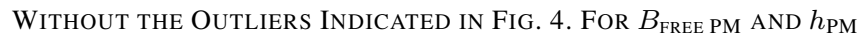
the Mean of the PM Adjacent to the Pole is Used.

\begin{tabular}{lcccc} 
& $B_{\delta}$ & $\delta$ & $B_{\text {free PM }}$ & $h_{\mathrm{PM}}$ \\
\hline$B_{\delta}$ & 1 & -0.65 & 0.51 & -0.26 \\
$\delta$ & -0.65 & 1 & -0.15 & 0.057 \\
$B_{\text {free }}$ & 0.51 & -0.15 & 1 & -0.023 \\
$h_{\mathrm{PM}}$ & -0.26 & 0.057 & -0.023 & 1
\end{tabular}

$\delta$, denoted $\mathrm{T}$ and $\mathrm{S}$, for definition see Section III, correlate closely. Generally the $\mathrm{S}$ measurement series is one tap size larger than the $\mathrm{T}$ measurement series, for a few poles they have the same value and for one pole the value differs by two tap sizes. Therefore, only the $\mathrm{S}$ measurement series is used here, since it is more representative of the air gap length at the position where the magnetic flux density is measured. The air gap length, $\delta$, for each rotor pole is shown in Fig. 5. It varies between $6.26 \mathrm{~mm}$ and $6.96 \mathrm{~mm}$, with an arithmetic mean of $6.64 \mathrm{~mm}$ and a standard deviation of $0.16 \mathrm{~mm}$.

The thickness of the PMs, $h_{\mathrm{PM}}$, is shown in Fig. 6. The thickness of the PMs varies between $37.5 \mathrm{~mm}$ and $38.7 \mathrm{~mm}$, with a mean of $38.13 \mathrm{~mm}$ and a standard deviation of $0.24 \mathrm{~mm}$.

The correlation coefficients for $B_{\delta}, \delta, B_{\text {free } \mathrm{PM}}$, and $h_{\mathrm{PM}}$, are calculated, with the poles affected by the outliers, indicated in Fig. 4, removed. The results are shown in Table II. The correlation coefficients of $\delta$ and the shifted $h_{\mathrm{PM}}$ are within \pm 0.2 and showed no discernible pattern.

To better visualize the correlations, each of the measured variables are normalized by their respective mean values and plotted in Fig. 7.

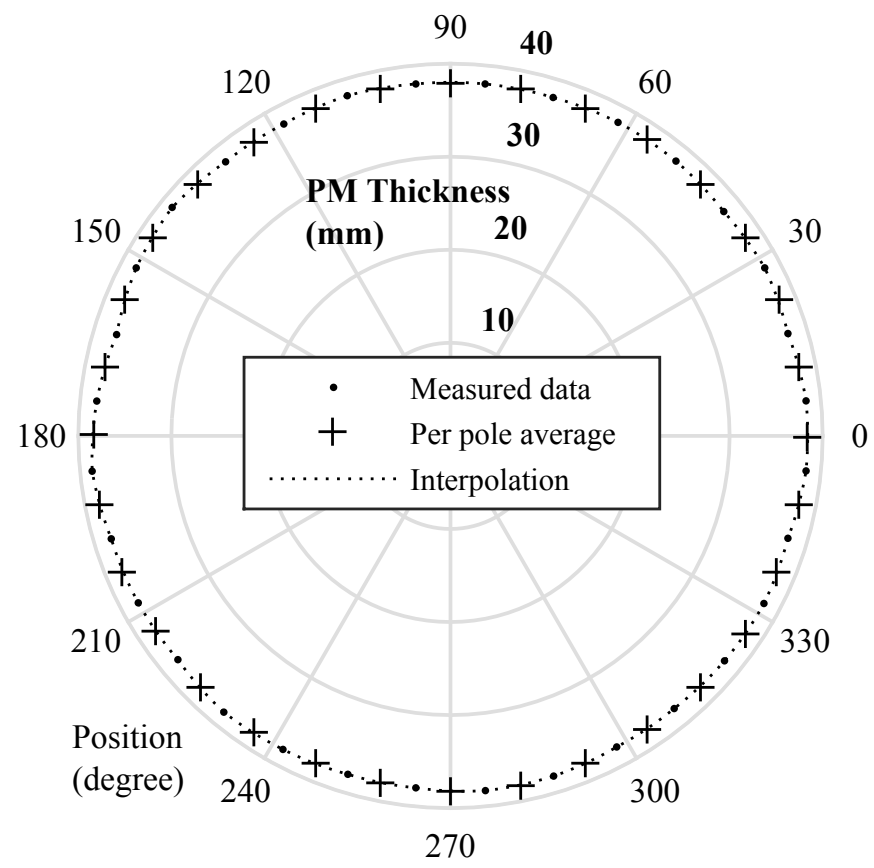

Fig. 6. Thickness of PMs, both direct measurement and per pole averages.

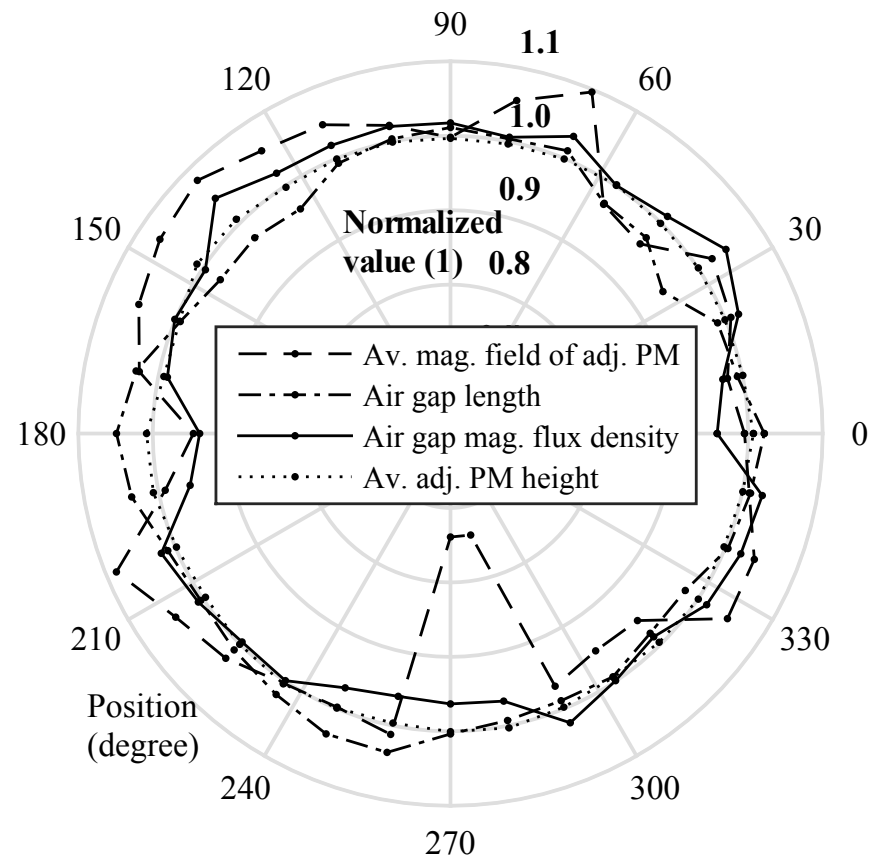

Fig. 7. The measured parameters normalized by their respective arithmetic mean. Note that the radial scale has 0.6 at the center, and not zero, to make the variations clearer, and that per pole means are used for $B_{\text {free PM }}$ and $h_{\mathrm{PM}}$.

The UMP due to the rotor imperfection is calculated to $1.5 \mathrm{kN}$ in the direction of $66^{\circ}$ of the polar plots. The mean magnetic force per pole is $2.5 \mathrm{kN}$ with a standard deviation of $0.13 \mathrm{kN}$.

The no load voltage is measured at a speed of $44 \mathrm{rpm}$ and an electrical frequency of $11.7 \mathrm{~Hz}$. The table for calculating $B_{r}$ from $B_{\text {free PM }}$ show that for $B_{r}$ in the range $0 \mathrm{~T}$ to $0.46 \mathrm{~T}$ 
TABLE III

TABle Comparing Nominal and Measured Quantities. For Nominal Values, the \pm -VAlues are Tolerances Given by the Manufacturer. The Measured Values are Given as Mean and Maximum Positive and Negative Deviation from the Mean. The "VERIFICATION" COLUMN ARE VALUES USED IN (IN ITALICS) OR CALCUlated FROM A Simulation WiTH $\delta$ AND $B_{r}$ FROM MEASUREMENTS.

\begin{tabular}{lccc} 
Quantity & Nominal & Measured & Verification \\
\hline $\begin{array}{l}\text { Air gap width } \delta \\
(\mathrm{mm})\end{array}$ & 7 & $6.6+0.3 /-0.4$ & 6.6 \\
PM Thickness (mm) & $38 \pm 0.1$ & $38.1+0.6 /-0.6$ & 38 \\
$B_{r}(\mathrm{~T})$ & $0.45 \pm 0.01$ & $0.38+0.04 /-0.06$ & 0.38 \\
$B_{\delta}(\mathrm{T})$ & 0.70 & $0.61+.03 /-0.04$ & 0.61 \\
No load RMS volt- & 50.4 & $40.9 \pm 0.1$ & 44.0 \\
age at 44 rpm (V) & & &
\end{tabular}

the expression

$$
B_{r}=5.29 B_{\text {free PM }}
$$

can be used. Data for comparison between design simulations, measured values, and a model verification simulation are given in Table III.

\section{DISCUSSION}

From Table II it can be seen that the correlation with $B_{\delta}$ is the strongest correlation for each of the variables. Further, an increasing $\delta$ correlates with a decreasing $B_{\delta}$,

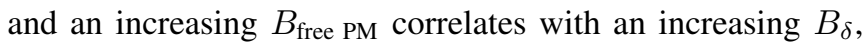
where $B_{\text {free PM }}$ is proportional to $B_{r}$ of the PM. Both of these correlations are what magnetic circuit theory predicts.

Not in accord with magnetic circuit theory is that increasing $h_{\mathrm{PM}}$ correlates, weakly, with decreasing $B_{\delta}$. A thicker PM should provide more magnetomotive force (MMF) than a thinner one, and give a larger magnetic flux density in the air gap. One possibility is that most of the excess PM thickness is caused by the adhesive, holding the pieces of the PM together. This would not only mean that no extra MMF is introduced, but also the introduction of additional effective air gap length.

Table III shows that the 2D simulation is a good predictor of magnetic flux density some distance into the air gap: the verification simulation predicts the mean value of the measurements of $0.61 \mathrm{~T}$. Induced voltage should be proportional to the magnetic flux density in the air gap and therefore be the same in the simulation and measurement. This is not the case since the simulation does not account for end effects. If one compares the measured voltage to that of the simulation it indicates that about 2.0 to 2.5 air gap lengths of effective machine length are lost due to the end effects, which seems reasonable. A measurement of the distribution of the air gap flux density in axial direction near the end of the machine would probably be able to indicate how far into the air gap the end effects extend.

The induced voltage is lower than expected, which will have implications for operation of the generator. While it is possible to generate the same power, a higher current will be necessary which in turn will increase the copper losses. The lower magnetic flux density will, however, cause a decrease in magnetization power losses, that partially cancel the increase of the total losses.

The nominal PM thickness, instead of measured, is used in the verifying simulation, since most of the excess thickness is judged to be due to adhesive between the parts of the PM, as well as the difference being very small.

It is unexpected how well the magnetic flux density in the middle of the free PM allowed the remanence to be predicted. When inserting the predicted remanence of $0.38 \mathrm{~T}$ in the verifying simulation, a $B_{\delta}$ of $0.61 \mathrm{~T}$ is calculated, which coincides with the mean of the measured $B_{\delta}$. While the measurement of $B_{\text {free PM }}$ is possibly sensitive to defects in the surface of the PM it still gave good agreement on average. To improve the results, a more sophisticated method can be devised. Such a method would include measuring the magnetic flux density in more than one point as well as for different applied magnetizing fields, to determine both the remanent magnetic flux density and the recoil permeability. Another approach would be to measure the total magnetic dipole moment of the PM.

There are a few factors that could affect the magnetic flux density in the air gap that have not been investigated. Material properties of the magnetically soft iron of the pole pieces and stator is one. Another one is the impact of PM material lost from the PMs due to flakes cracking away from the PM during insertion. While the mass of material that is lost during insertion is about half a percent of the total mass of the PM, the volume of missing PM may cause unexpected effects.

There are a few mechanical factors that can explain the variation in the air gap length. The measurements are made in the upper part of the air gap while, the alignment pins for the pole pieces are located at the bottom end. Combined with the magnetic forces and pressure from tightly fitted PMs, this could make the upper part of the pole piece tilt slightly toward the stator. The $\mathrm{T}$ measurement series of the air gap length generally give a smaller air gap length than the S series; which indicates that this may be the case. In addition, the pins that are used to align the pole pieces are of slotted spring-type instead of solid, which could decrease the precision of the alignment of the pole pieces somewhat. As mentioned in the introduction, several of the PMs are above the upper tolerance in thickness. This probably contributed to the rotor diameter being slightly larger than it should be. No correlation between the air gap length at a given pole, and thickness of the PMs adjacent to it, or a number of poles further away, is found.

The deviation in thickness of the PM blocks is probably due to that they are not sintered in a single piece but rather glued together from multiple pieces. This makes it possible that two pieces, both at the upper tolerance limit, gets glued together. Also, if the adhesive is not properly compressed, this can increase the thickness of the final PM block.

The remanence of the PMs seems to be well below its tolerance, and the cause remains unclear. The two main 
possible causes are production errors, with the PM not getting the proper magnetization from the start, and transport damage, where the PM gets partially demagnetized during transport. For ferrite PMs the latter can be a bigger problem than with for instance $\mathrm{NdFeB}$ since their intrinsic coercivity has a positive temperature coefficient and the PMs might, at some point, be subjected to low temperature during long distance shipping.

The UMP is well below what the mechanical design can handle and should not pose a problem.

\section{CONCLUSIONS}

The impact of manufacturing tolerance on the electromagnetic performance is investigated for a generator with a spoke-type ferrite permanent magnet rotor. In the spoke-type rotor there is a number of consecutive parts, where the chain of tolerances give the final tolerance on the air gap length. This makes investigation of the air gap length variation in a machine with such a rotor interesting. In addition, the magnetic tolerance of the ferrite magnets will affect the air gap magnetic flux density.

Measurements of the air gap length show that it is, on average, $5 \%$ smaller than nominal. This highlights the need for correct positioning of the pole pieces, even though the smaller air gap length does not cause a problem in the studied machine. Steps should be taken to ensure that both ends of each of the pole pieces are in the correct position, relative to the generator shaft. A useful estimate of the remanence of a permanent magnet is made by measuring the normal component of the magnetic flux density near its surface, when it is placed far from other ferromagnetic objects. The measurement reveals that the remanence is $16 \%$ below its nominal value; to a large extent explaining the lower than nominal air gap magnetic flux density measured. The method for estimating the remanence should be further investigated, as its simplicity allows it to be used in quality control when building PM machines. The statistical analysis shows that the air gap magnetic flux density has the expected correlation with both the air gap length and the remanence. The unbalanced magnetic pull, estimated from the inter-pole inequality in air gap magnetic flux density, is small compared to what the structure can withstand, and should not pose a problem.

\section{ACKNOWLEDGMENT}

The authors wish to thank Svante Andersson for helpful discussion and input on measurement of the air gap length.

\section{REFERENCES}

[1] S. Eriksson and H. Bernhoff, "Rotor design for pm generators reflecting the unstable neodymium price," in XXth International Conference on Electrical Machines (ICEM), Sept 2012, pp. 1419-1423.

[2] P. Eklund, S. Sjökvist, S. Eriksson, and M. Leijon, "A complete design of a rare earth metal-free permanent magnet generator," Machines, vol. 2, no. 2, p. 120, 2014. [Online]. Available: http://www.mdpi.com/2075-1702/2/2/120

[3] K. Binns and A. Kurdali, "Permanent-magnet a.c. generators," Proceedings of the Institution of Electrical Engineers, vol. 126, no. 7, pp. 690-696, July 1979.

[4] S.-M. Jang, H.-J. Seo, Y.-S. Park, H.-I. Park, and J.-Y. Choi, "Design and electromagnetic field characteristic analysis of $1.5 \mathrm{~kW}$ small scale wind power generator for substitution of nd-fe-b to ferrite permanent magnet," IEEE Transactions on Magnetics, vol. 48, no. 11, pp. 2933 2936, Nov 2012.

[5] I. Coenen, M. van der Giet, and K. Hameyer, "Manufacturing tolerances: Estimation and prediction of cogging torque influenced by magnetization faults," IEEE Transactions on Magnetics, vol. 48, no. 5, pp. 1932-1936, May 2012.

[6] Z. Zhu, Z. Azar, and G. Ombach, "Influence of additional air gaps between stator segments on cogging torque of permanent-magnet machines having modular stators," IEEE Transactions on Magnetics, vol. 48, no. 6, pp. 2049-2055, June 2012.

[7] L. Gasparin, A. Cernigoj, S. Markic, and R. Fiser, "Additional cogging torque components in permanent-magnet motors due to manufacturing imperfections," IEEE Transactions on Magnetics, vol. 45, no. 3, pp. 1210-1213, March 2009.

[8] G. Heins, T. Brown, and M. Thiele, "Statistical analysis of the effect of magnet placement on cogging torque in fractional pitch permanent magnet motors," IEEE Transactions on Magnetics, vol. 47, no. 8, pp. 2142-2148, Aug 2011.

[9] A. Kallaste, A. Belahcen, and T. Vaimann, "Effect of PM parameters variability on the operation quantities of a wind generator," in IEEE Workshop on Electrical Machines Design, Control and Diagnosis (WEMDCD), March 2015, pp. 242-247.

[10] A. Kallaste, T. Vaimann, and A. Belahcen, "Possible manufacturing tolerance faults in design and construction of low speed slotless permanent magnet generator," in 16th European Conference on Power Electronics and Applications (EPE'14-ECCE Europe), Aug 2014, pp. $1-10$.

\section{BIOGRAPHIES}

Petter Eklund was born in Uppsala, Sweden in 1989. He received the MSc degree in energy systems engineering from Uppsala University in 2013 and is currently a $\mathrm{PhD}$ student at the Division of Electricity, Department of Engineering Sciences, of Uppsala University. His main research interest is design of low speed permanent magnet generators that does not use rareearth permanent magnets.

Sandra Eriksson was born in Eskilstuna, Sweden, in 1979. She finished her MSc in Engineering Physics at Uppsala University, Sweden in 2003 and studied toward a $\mathrm{PhD}$ degree in engineering science with a specialization in science of electricity between 2004 and 2008. She currently holds a position as associate professor at the Division of Electricity, Department of Engineering at Uppsala University. Her main topics of interest are design of permanent magnet electrical machines, alternative permanent magnet materials as well as control strategies and electrical system for wind turbines. 